\title{
Urinary isoflavone kinetics: the effect of age, gender, food matrix and chemical composition
}

\author{
Marian S. Faughnan ${ }^{1}$, Ann Hawdon ${ }^{1}$, Eric Ah-Singh ${ }^{1}$, Jonathan Brown ${ }^{1}$, D. J. Millward ${ }^{1}$ and \\ Aedin Cassidy ${ }^{1,2 *}$ \\ ${ }^{1}$ School of Biological Sciences, University of Surrey, Guildford GU2 5XH, UK \\ ${ }^{2}$ School of Medicine, Health Policy + Practice, University of East Anglia, Norwich NR4 7TJ
}

(Received 16 July 2003 - Revised 28 November 2003 - Accepted 17 December 2003)

\begin{abstract}
Urinary isoflavone excretion is used to monitor compliance and examine biological effects. The present study determined if there were alterations in urinary isoflavone excretion following the ingestion of different soya foods and if age and gender potentially modified profiles. Twenty premenopausal women, seventeen post-menopausal women and twenty men received a defined single oral bolus dose $(0.44 \mathrm{mg}$ isoflavones $/ \mathrm{kg}$ body weight) of soya milk, textured vegetable protein (TVP) or tempeh on three separate occasions. Baseline and four consecutive complete $24 \mathrm{~h}$ pooled urines were collected during each period. Urinary genistein recovery was influenced by gender and food matrix. For women the urinary genistein recovery was higher following soya-milk consumption compared with TVP $(P<0.05)$. Tempeh consumption also resulted in an increased urinary genistein recovery relative to soya milk in premenopausal women $(P<0.052)$. No differences in urinary genistein recoveries between soya foods were observed in the men. Although urinary daidzein excretion was similar across the foods studied and was not affected by age or gender, conversion to its intestinal metabolite, equol, resulted in potential matrix and chemical composition effects; urinary equol excretion was higher $(P<0 \cdot 01)$ following tempeh ingestion among equol producers. Together these data suggest that the fractional absorption of genistein is potentially different in men and women and is influenced by the food matrix and chemical composition. Furthermore, the data suggest that the metabolism of daidzein may be altered by the chemical composition of the isoflavones ingested. Further studies are required to examine the effect of higher intake and define the relative influence of these factors in elderly population groups.
\end{abstract}

Soya: Isoflavones: Bioavailability

Although there has been interest in the potential risks and benefits of consuming diets rich in soya phyto-oestrogens over the last decade (Setchell \& Cassidy, 1999), to date limited research has been conducted to determine the bioavailability of isoflavones from soya foods and define the relative importance of factors such as age and gender on levels attained in vivo. The metabolism of isoflavones in animals and man is complex, and is a combination of both mammalian and gut microbial processes (Setchell \& Cassidy, 1999, Rowland et al. 2003; Setchell, 2000). After ingestion, isoflavones are hydrolysed by intestinal glucosidases, which release the aglycones daidzein, gensitein and glycitein. These may be absorbed or further metabolised to many specific metabolites including equol and p-ethyl phenol (Axelson et al. 1984; Bannwart et al. 1984; Kelly et al. 1993; Joannou et al. 1995). Because there are currently no guidelines on optimal levels of isoflavones and there are limited data on their bioavailability from foods (Xu et al. 1994; Setchell et al. 2001, 2003a,b), dietary intakes in clinical studies examining the risks and benefits of isoflavones for human health have to date been empirically derived. The daily intake of around $50 \mathrm{mg}$ isoflavones/d, which has predominantly been used in clinical intervention studies, appears to be largely based on our earlier observation that the daily consumption of soya foods containing $45 \mathrm{mg}$ isoflavones caused endocrine modulation of the menstrual cycle in healthy premenopausal women (Cassidy et al. 1994, 1995). More recently there has been a tendency to use relatively large dietary intakes of soya isoflavones derived from foods or supplements far exceeding typical consumption levels in Asian countries, which range from $15-50 \mathrm{mg} / \mathrm{d}$ (Nagata et al. 1998; Chen et al. 1999; Wakai et al. 1999). However, the rationale for these higher intakes remains unclear and is not based on the knowledge of isoflavones' pharmacokinetic behaviour. As with pharmacological compounds, demonstrating the efficacy of soya and its isoflavones requires knowledge of their bioavailability but to date there is limited information on how this varies among subjects and whether it is influenced by age or other factors.

Although it is well established that infants, in contrast to adults, are unable to metabolise isoflavones (Setchell et al. 
1997), to date there are no data available examining the effect of age on isoflavone metabolism and absorption in later life. This is particularly important since much of the current interest in relation to isoflavones relates to the health of post-menopausal women, but to date many studies investigating the biological effects of these compounds have been carried out in premenopausal women (Cassidy et al. 1994, 1995). Furthermore, the influence of gender is contentious with several studies suggesting that urinary isoflavone kinetics are not related to gender (Setchell et al. 1984; Kelly et al. 1993; Kirkman et al. 1995; Lampe et al. 1998) while others are suggestive of a gender difference in the absorption and metabolism of these compounds (Lu \& Anderson, 1998).

In Asian countries where soya is consumed as a staple it remains to be determined if the chemical composition of the soya food alters absorption and metabolism and thus the potential biological efficacy of soya isoflavones. Asian populations have traditionally consumed primarily fermented soya protein products, and since these foods contain a higher proportion of aglycone isoflavones, it has been suggested that they may be more bioavailable since these aglycone isoflavones do not require hydrolysis in the intestine before absorption. There are preliminary suggestions that urinary recoveries of daidzein and genistein following the ingestion of fermented soya foods may be greater (Cassidy et al. 1995; Hutchins et al. 1995). However, this contrasts with recent data on the pure compounds, which suggest no differences in the apparent bioavailability of pure daidzein and gensitein tablets when consumed as either aglycones or glycosides (Zubik \& Meydani, 2003). Although in their purified form, daidzein and genistein aglycones are more rapidly absorbed into the systemic circulation (Izumi et al. 2000; Setchell et al. 2001), other data suggest that the overall systemic bioavailability of the pure aglycone compounds is lower compared with their glycoside forms (daidzein and genistein; Setchell et al. 2001). However, whether the same effects are observed when subjects are fed different soya foods containing isoflavones in the conjugated or unconjugated form remains to be investigated.

In human intervention trials investigating the biological effects of these compounds in relation to human health, urinary phyto-oestrogens are frequently used as a biomarker of their potential bioavailability from foods or supplements rich in these compounds. This is in part because urine is an easier biological sample to collect, and because urine contains 100 -fold higher concentrations of isoflavones (Cassidy et al. 1994; Setchell et al. 2001, $2003 a, b$ ). Our recent data from pharmacokinetic studies using stable isotopes of the pure isoflavone compounds, daidzein and genistein, suggest that the collection of random urine samples does not correlate with serum measurements, but $24 \mathrm{~h}$ urine collections monitored for completeness with an exogenous marker correlate well with serum assessment of systemic bioavailability of these compounds (Setchell et al. 2003b). Additionally, quantitative assessment in urine provides information on the extent of intestinal metabolism of isoflavones and provides information on subject compliance within soya intervention trials.

Knowledge of the factors that influence urinary isoflavone excretion will be key to optimising the intake of soya foods in subgroups of the population. The aim of the present study was to evaluate the effect of age, gender, food matrix, and chemical composition on the urinary excretion of the soya isoflavones, daidzein and genistein, and the daidzein metabolite, equol.

\section{Methods}

Foods

In order to examine the effect of the food matrix on urinary levels of isoflavones, a commercially available soya milk (Sanitarium, NSW, Australia), and a source of textured vegetable protein (TVP; Goodness Foods, Daventry, UK) were purchased. The chemical composition of the soya foods was compared using tempeh (Impulse Foods, Rooksbridge, Somerset, UK) as a source of predominantly unconjugated isoflavones over the 1.5 -year period of the study. Two batches of commercially available soya milk and tempeh and one batch of TVP were used. The isoflavone content of each batch was analysed using the method of Setchell et al. (1997) (see Table 1) and the levels fed to the subjects were adjusted to ensure that the total isoflavone levels fed remained constant throughout the study periods.

The soya milk was administered as purchased and provided a liquid soya-food matrix in which the isoflavones were predominantly found as conjugates (Table 1). The TVP (solid matrix) also contained isoflavones predominantly in the conjugated form (Table 1) and was given to each subject as bread rolls, which had been prepared in advance and

Table 1. Isoflavone content of soyabean products as purchased (following analysis by the method of Setchell et al. 1997)

\begin{tabular}{|c|c|c|c|c|c|}
\hline \multirow[b]{2}{*}{ Food } & & \multicolumn{3}{|c|}{$\begin{array}{c}\text { Isoflavone content } \\
\text { ( } \mu \mathrm{g} \text { aglycone equivalents/g) }\end{array}$} & \multirow{2}{*}{$\begin{array}{l}\text { Percentage daidzein and } \\
\text { genistein in aglycone form }\end{array}$} \\
\hline & & Total & Daidzein & Genistein & \\
\hline \multirow[t]{2}{*}{ Soya milk } & Batch 1 & 63.9 & $19 \cdot 6$ & $22 \cdot 3$ & $14 \cdot 1$ \\
\hline & Batch 2 & $50 \cdot 3$ & $15 \cdot 2$ & $28 \cdot 3$ & 5.9 \\
\hline TVP & Batch 1 & $476 \cdot 0$ & $163 \cdot 1$ & $312 \cdot 8$ & $8 \cdot 2$ \\
\hline \multirow[t]{2}{*}{ Tempeh } & Batch 1 & 234.4 & $72 \cdot 4$ & $140 \cdot 3$ & $50 \cdot 0$ \\
\hline & Batch 2 & $345 \cdot 6$ & $137 \cdot 1$ & $186 \cdot 4$ & $48 \cdot 1$ \\
\hline
\end{tabular}

TVP, textured vegetable protein. 
stored at $-20^{\circ} \mathrm{C}$ until required. The tempeh (solid soya-food matrix) contained a significant proportion of isoflavones in the aglycone form (Table 1). It was prepared into burgers and frozen at $-20^{\circ} \mathrm{C}$ until required. The variability between the batches of both soya milk and tempeh was also tested but no statistical differences were found in the recoveries between the batches of foods.

\section{Subjects}

The subjects were recruited from the staff and student population at the University of Surrey and surrounding area. Twenty premenopausal women, seventeen post-menopausal women and twenty men were recruited to participate in the present studies. All individuals were healthy, reported no use of medications, including antibiotics (previous 6 months) and were not regular consumers of soya foods. The premenopausal women reported regular menstrual cycles and were not currently using oral contraceptives or hormone-releasing contraceptive devices. The post-menopausal women reported no menstrual bleeding for at least 2 years. Healthy men between the ages of 18 and 55 years were recruited. The ethics committee of the University of Surrey approved the study protocol. Informed written consent was obtained following a full explanation of the study protocol to each subject.

\section{Study design}

Subjects were studied on three separate occasions and were randomly assigned to receive a different soya food on three occasions. Subjects were instructed and asked to adhere to a soya-free diet for 1 month before and for the duration of the study. Following an overnight fast they arrived at the Clinical Investigation Unit at the University of Surrey and received a $0.44 \mathrm{mg}$ soya isoflavones $/ \mathrm{kg}$ body weight dose as soya milk, TVP rolls or tempeh burgers on three separate occasions under supervision. Each dose was separated by a minimum of a 2 -week washout period.

Each subject collected a baseline $24 \mathrm{~h}$ urine collection before the ingestion of each soya food. All subjects continued to complete consecutive pooled $24 \mathrm{~h}$ urine collections for the following $4 \mathrm{~d}$. The volume of each $24 \mathrm{~h}$ pooled urine collection was recorded and $30 \mathrm{ml}$ homogeneous samples were stored at $-80^{\circ} \mathrm{C}$ for analysis. To check the completeness of each collection, all subjects consumed $3 \times 80 \mathrm{mg} p$-aminobenzoic acid (Laboratory of Applied Biology Ltd, London, UK) daily during the $5 \mathrm{~d}$ of urine collections and the recovery of this marker was measured (Bingham \& Cummings, 1983).

\section{Urinary isoflavones analysis}

Urinary daidzein, genistein and equol concentrations were determined by a modification of the GC-MS methods previously described by Setchell et al. (1984).

Following the addition of internal standards (500 ng each of $\left[{ }^{13} \mathrm{C}\right]$ daidzein, $\left[{ }^{13} \mathrm{C}\right]$ genistein and $\left[{ }^{13(3)} \mathrm{C}\right]$ equol $)$, the urine $(0.5 \mathrm{ml})$ was hydrolysed overnight at $37^{\circ} \mathrm{C}$ in $0.1 \mathrm{ml}$ Helix pomatia extract (Sigma-Aldrich Chemical Co., Poole, UK). The samples were then acidified using 2
M-acetic acid $(100 \mu \mathrm{l})$ and the isoflavones extracted in diethyl ether. The phenolic fraction was dried under a stream of $\mathrm{N}_{2}$ at $65^{\circ} \mathrm{C}$. tert-Butyldimethylsilyl ether derivatives were formed by the addition of acetonitrile $(100 \mu \mathrm{l})$ and $N$-methyl- $N$ - $t$-butyldimethylsilyltrifluoroacetamide in $1 \% t$-butyldimethylchlorosilane $(100 \mu \mathrm{l})$ and incubation at $65^{\circ} \mathrm{C}$ for $2 \mathrm{~h}$.

The isoflavone tert-butyldimethylsilyl ether derivatives were chromatographically separated and quantified using selective ion monitoring GC-MS. Separation occurred on a DB-1 column $(15 \mathrm{~m} \times 0.25 \mathrm{~mm}$ internal diameter, $0.10 \mathrm{~mm}$ film thickness; J \& W Scientific, Folsom, CA, USA) with $\mathrm{He}$ as the carrier gas and a temperature programme from 200 to $280^{\circ} \mathrm{C}$ with increments of $30^{\circ} \mathrm{C} / \mathrm{min}$, held for $6 \mathrm{~min}$. The following ions were monitored for daidzein, $\left[{ }^{13} \mathrm{C}\right]$ daidzein, genistein, $\left[{ }^{13} \mathrm{C}\right]$ genistein, equol, and $\left[{ }^{13} \mathrm{C}\right]$ equol: mass:charge ratio $(\mathrm{m} / \mathrm{z}) 425, \mathrm{~m} / \mathrm{z} 426$, $\mathrm{m} / \mathrm{z} 555, \mathrm{~m} / \mathrm{z} 556, \mathrm{~m} / \mathrm{z} 470$ and $\mathrm{m} / \mathrm{z} 473$ respectively. The quantification of isoflavone levels was determined by comparing the peak area in the specific ion channels, at the retention time of the ether derivative corresponding to the compound, compared with the ${ }^{13} \mathrm{C}$-labelled internal standard.

A repeat analysis of a pooled sample of urine from subjects consuming soya food was used as a quality control during the analysis of each batch of samples. The mean between-batch reproducibility (CV) for daidzein, genistein and equol was $11.9,9.3$ and $12.8 \%$ respectively and within-batch reproducibility $(\mathrm{CV})$ for daidzein, genistein and equol was 4,3 and $7 \%$ respectively.

\section{Statistical analyses}

Data analysis was carried out using the Statistical Analysis Systems statistical software package (SAS Institute, Cary, NC, USA). All data are expressed as mean values with their standard errors unless otherwise stated. A two-way ANOVA model was fitted to the data to account for the two fixed effects, being group (i.e. premenopausal women, post-menopausal women or men) and food (i.e. soya milk, TVP or tempeh). A fixed effect according to the interaction between these two fixed effects (food $X$ group effect) was included if significant. A random effect was also fitted to the model to account for intra-individual variation. Tukey-Kramer methods were used for multiple testing. Urinary recovery is expressed as aglycone equivalents ingested.

\section{Results}

\section{Subject characteristics and compliance}

The age ranges of the premenopausal women, post-menopausal women and men were 18-53, 48-69 and 18-55 years respectively. Doses of isoflavones were fed on a $\mathrm{mg} / \mathrm{kg}$ body-weight basis and the subjects' body weights ranged from 54 to $110 \mathrm{~kg}$. BMI was not significantly different between the groups and ranged from 16 to $34 \mathrm{~kg} / \mathrm{m}^{2}$. Compliance with the test diet was determined using the exogenous marker, $p$-aminobenzoic acid (Bingham \& Cummings, 1983), and only those subjects who provided 
complete $24 \mathrm{~h}$ pooled urine collections across all three soya-food periods were included in the final analysis; fourteen premenopausal women, thirteen post-menopausal women and fifteen men.

\section{Urinary daidzein and genistein recovery}

The mean daily urinary recoveries of daidzein and genistein following challenges with the different soya foods are shown in Fig. 1. With all three foods tested, the majority of daidzein and genistein was recovered in urine within the first $24 \mathrm{~h}$ following ingestion of the food. Low levels of daidzein and genistein were measurable on day 2 but by days 3 and 4 urinary excretion of these compounds was negligible and had returned to baseline levels (see Fig. 1). The mean urinary excretions of total daidzein and genistein on day 2 were 0.38 (SD 0.32), 0.37 (SD 0.36) and 0.46 (SD 0.41) $\mathrm{mg} / \mathrm{d}$ for milk, TVP and tempeh respectively. Urinary daidzein recovery in days 1 and 2 was consistently higher than that of urinary genistein over the three foods studied.

The absolute recovery ( $\mu \mathrm{mol}$ excreted) and dose recovered (corrected for aglycone equivalents) of the parent compounds following the ingestion of soya milk, TVP and tempeh are given in Fig. 2. A significant food effect $(P>0.0001$; ANOVA) was observed in absolute urinary isoflavone recovery with greatest recovery in the order of tempeh $>$ milk $>$ TVP (with a non-significant difference between soya milk and tempeh). However, after correction for the recovery of aglycone equivalents ingested, no real food effect was observed, suggesting that differences in
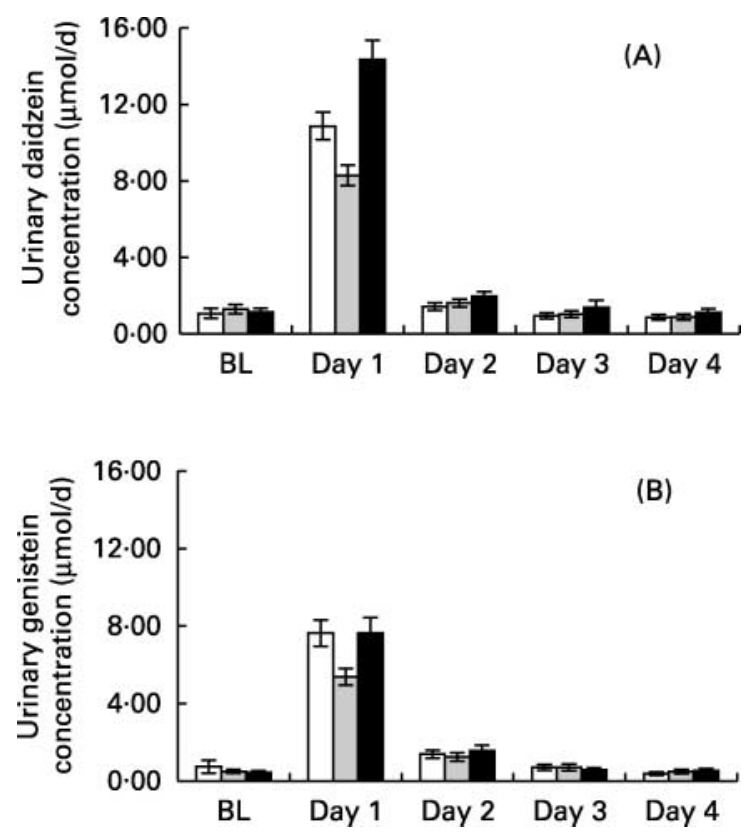

Fig. 1. Urinary daidzein (A) and genistein (B) excretion profiles at baseline (BL) and following challenge with $0.44 \mathrm{mg}$ isoflavones $/ \mathrm{kg}$ body weight of soya milk $(\square)$, textured vegetable protein $(\square)$ and tempeh (ם) in men ( $n$ 15), post-menopausal women $(n 13)$ and premenopausal women $(n 14)$. Mean values are shown, with standard errors represented by vertical bars. the isoflavone composition of the soya foods contributed to the proposed differences in recoveries between the foods studied. No group differences, i.e. between men and women, and between premenopausal and post-menopausal women were observed in absolute recovery or dose recovered.

Table 2 shows the cumulative daidzein and genistein excretion in the pooled urine collections. The cumulative excretion (percentage dose recovered) of daidzein did not differ between the groups or foods consumed, and no food $\times$ group interaction was noted. In contrast a significant food effect $(P<0.0001 ;$ ANOVA $)$ and a food $\times$ group interaction $(P=0.01$; ANOVA) was noted in the model for the cumulative urinary excretion of genistein (percentage dose recovered). In both groups of women no differences were observed in urinary genistein recovery between the TVP and tempeh diet periods but urinary recovery was significantly higher in both groups of women $(P<0.001$ and $P<0.05$, premenopausal and post-menopausal women respectively; ANOVA with Tukey-Kramer) when they were fed soya milk compared with the TVP study period. In premenopausal women, urinary genistein recovery was also significantly higher $(P<0.001 ;$ ANOVA with Tukey-Kramer) following milk ingestion compared with tempeh. A similar trend was observed for the post-menopausal women but it was not statistically significant. No difference in the recoveries of urinary genistein between soya foods was observed in the men. Between groups no significant difference in the recovery of genistein was observed following the ingestion of TVP and tempeh. However, following soya-milk ingestion, premenopausal
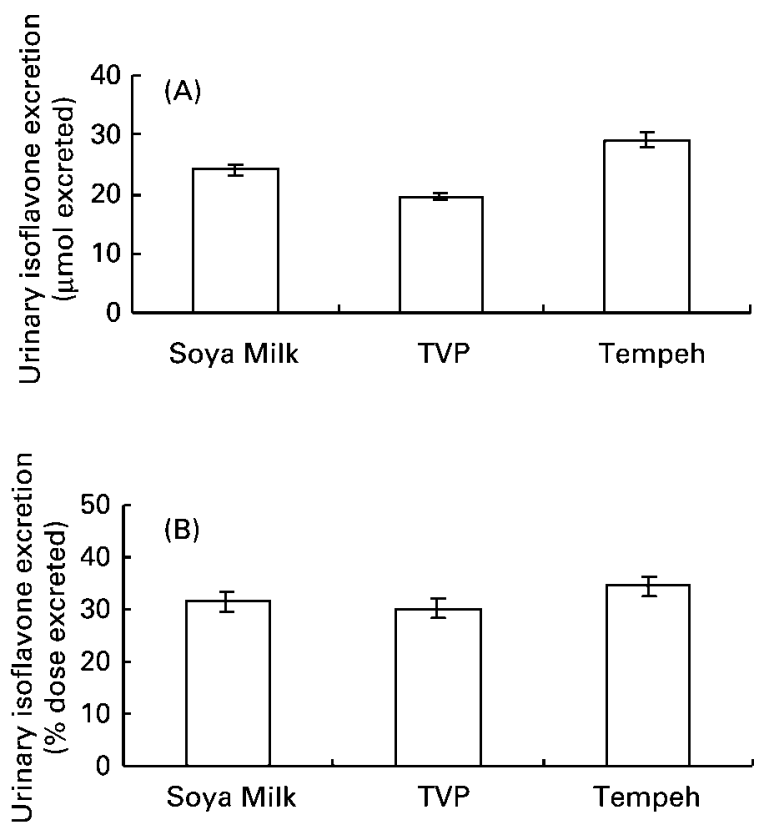

Fig. 2. Cumulative recovery of total daidzein and genistein over four consecutive days (pooled $24 \mathrm{~h}$ urine collections) following the ingestion of $0.44 \mathrm{mg}$ isoflavones $/ \mathrm{kg}$ body weight of soya milk, textured vegetable protein (TVP) and tempeh, expressed as (A) absolute recovery ( $\mu \mathrm{mol}$ excreted) and $(B)$ urinary recovery of ingested doses corrected for aglycone equivalents. Mean values are shown, with standard errors represented by vertical bars. 
Table 2. Cumulative urinary daidzein and genistein excretion over four pooled $24 \mathrm{~h}$ urine collections in subjects challenged with $0.44 \mathrm{mg}$ isoflavones/kg body weight as soya milk, textured vegetable protein (TVP) and tempeh

(Mean values with their standard errors)

\begin{tabular}{|c|c|c|c|c|c|c|c|c|c|c|c|c|}
\hline & \multicolumn{6}{|c|}{ Daidzein* } & \multicolumn{6}{|c|}{ Genistein* } \\
\hline & \multicolumn{2}{|c|}{$\begin{array}{l}\text { Premenopausal } \\
\text { women }(n 14)\end{array}$} & \multicolumn{2}{|c|}{$\begin{array}{l}\text { Post-menopausal } \\
\text { women }(n 13)\end{array}$} & \multicolumn{2}{|c|}{ Men $(n 15)$} & \multicolumn{2}{|c|}{$\begin{array}{l}\text { Premenopausal } \\
\text { women }(n 14)\end{array}$} & \multicolumn{2}{|c|}{$\begin{array}{l}\text { Post-menopausal } \\
\text { women }(n 13)\end{array}$} & \multicolumn{2}{|c|}{ Men $(n 15)$} \\
\hline & Mean & $\mathrm{SE}$ & Mean & SE & Mean & SE & Mean & SE & Mean & SE & Mean & $\mathrm{SE}$ \\
\hline Soya milk & $51 \cdot 6$ & $5 \cdot 0$ & $60 \cdot 6$ & 8.7 & $59 \cdot 2$ & 4.8 & $47 \cdot 1 \dagger \ddagger$ & $5 \cdot 7$ & $29.9 \S$ & $5 \cdot 4$ & 28.7 & $5 \cdot 2$ \\
\hline TVP & $49 \cdot 9$ & $4 \cdot 1$ & $45 \cdot 7$ & $6 \cdot 1$ & $53 \cdot 7$ & 4.9 & $18 \cdot 7$ & $2 \cdot 0$ & $14 \cdot 1$ & 1.8 & $21 \cdot 7$ & 3.8 \\
\hline Tempeh & 53.9 & 4.0 & $63 \cdot 6$ & 9.6 & 48.2 & 4.7 & $22 \cdot 8$ & $2 \cdot 0$ & 18.0 & $3 \cdot 0$ & $22 \cdot 2$ & 4.2 \\
\hline
\end{tabular}

* Data were analysed by a two-way ANOVA with group and food being the main effects. A significant food effect $(P<0.0001)$ and a food $\times$ group interaction $(P=0.01)$ were noted in genistein recovery.

$\dagger$ For genistein recovery, mean value was marginally significantly different from that for men $(P=0.052)$ (ANOVA with Tukey-Kramer test).

¥ For genistein recovery, mean value was significantly different from those for TVP and tempeh $(P=0.001)$ (ANOVA with Tukey-Kramer test)

$\S$ For genistein recovery, mean value was significantly different from that for TVP $(P<0.05)$ (ANOVA with Tukey-Kramer test).

women had a higher $(P<0.052$; ANOVA with TukeyKramer) recovery of genistein compared with the men.

\section{Urinary equol excretion}

The urinary equol excretion profiles are shown in Fig. 3. As expected, equol appeared in the urine during days 1 and 2 following the ingestion of soya foods, slowly returning to baseline levels during day 4. Six premenopausal women, four post-menopausal women and one male consistently excreted equol following the ingestion of the three soya foods. One premenopausal woman excreted equol following tempeh ingestion and three men each excreted equol only following the ingestion of one soya food (each a different soya food). The cumulative urinary recovery of equol was significantly higher following tempeh ingestion compared with the other two soya foods $(P<0 \cdot 01$; ANOVA).

\section{Discussion}

There is currently little information on factors that influence the bioavailability of soya isoflavones from food. Previous bioavailability studies have tended to focus on the urinary excretion of the isoflavones and their metabolites following the ingestion of purified compounds or a single food source or in a single population group (Cassidy et al.

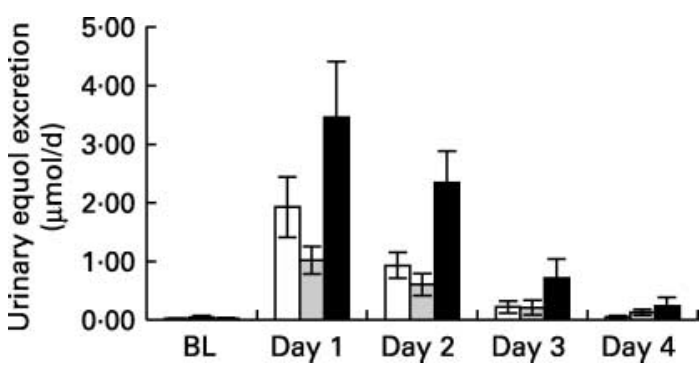

Fig. 3. Urinary equol excretion over the study period following the ingestion of a single dose of $0.44 \mathrm{mg}$ isoflavones $/ \mathrm{kg}$ body weight as soya milk $(\square)$, textured vegetable protein $(\square)$ and tempeh (ם). Mean values are shown, with standard errors represented by vertical bars. Two male subjects (13\%) produced equol, while ten to eleven women produced equol (37-41\%).
1994; King \& Bursill, 1998; Izumi et al. 2000; Setchell et al. 2001, 2003a,b; Zubik \& Meydani, 2003). In the present study, the influence of age, gender, food matrix and chemical composition on the levels of daidzein and genistein and the daidzein metabolite, equol, in urine were determined.

In agreement with previous studies, wide inter-individual variability in the urinary recovery of daidzein and genistein was observed (Karr et al. 1997; Rowland et al. 1999). In the present study ( $n$ 42), the recovery of total daidzein and genistein was 31.1 and $13.0 \%$ respectively of total isoflavones ingested, with daidzein and genistein recoveries ranging from 8 to $100 \%$ and 4 to $94 \%$ respectively.

The use of urinary isoflavone excretion is widespread in clinical trials as a marker of compliance with the dietary intervention and as an assessment of the bioavailability of these compounds from soya foods and supplements. It is well established that following soya-food consumption, urinary daidzein concentrations are consistently higher than urinary genistein levels (King \& Bursill, 1998; Watanabe et al. 1998; Zhang et al. 1999; Setchell et al. 2003b). This suggests that the fraction of ingested daidzein absorbed is greater than that of genistein. Conversely, the daidzein:genistein ratio is reversed in blood when equal amounts of the two compounds are ingested resulting in greater bioavailability of genistein than daidzein in the systemic circulation (Setchell et al. 2003b). In a recent study using stable isotopes of daidzein and genistein we demonstrated a weak correlation between serum and urinary isoflavone concentrations (Setchell et al. 2003b). However, total $24 \mathrm{~h}$ urinary isoflavone output ( $\mu \mathrm{mol}$ ) (monitored for completeness using an exogenous marker) correlated highly with serum concentrations demonstrating the necessity for complete $24 \mathrm{~h}$ urine collections when investigating the physiological behaviour of these compounds and providing the rationale for this approach in the present study.

The excretion profiles of daidzein and genistein over the $96 \mathrm{~h}$ following the ingestion of the soya foods are similar to that which we previously observed (Setchell et al. $2003 a, b)$, with the majority appearing in the urine within the first $24 \mathrm{~h}$ following the ingestion of the soya food. 
This rapid appearance of these compounds in urine can be explained by the short serum half-life and fast serum clearance rates of both daidzein and genistein. Other investigations of the urinary excretion patterns of these compounds following acute ingestion have also reported low excretion rates $24 \mathrm{~h}$ post ingestion (King \& Bursill, 1998; Watanabe et al. 1998; Setchell et al. 2003b).

The present study aimed to evaluate the potential impact that age, gender, food matrix and chemical composition may have on urinary isoflavone excretion following the consumption of a single portion of three soya foods in the same group of subjects. Absolute urinary recovery of daidzein and genistein was significantly greater following the ingestion of tempeh than that of the other two foods and there was a trend towards higher excretion following TVP than tempeh. However, to validly compare the three foods and groups it was essential that urinary excretion was expressed as percentage dose ingested following correction for aglycone equivalents, as although a fixed dose (per $\mathrm{kg}$ body weight) was given to each individual, the foods differed in composition of isoflavones. After correcting for aglycone levels in the foods, there was no difference in total urinary isoflavone excretion. Daidzein recovery remained similar across the groups studied for the three soya foods. However, genistein urinary output was altered by the test food studied and other factors.

The urinary recovery of genistein appeared to be influenced by gender and food matrix. In the men studied, there was no difference in the recovery of genistein across the three foods whereas urinary genistein recovery was different in the women depending on the soya food fed. Lu \& Anderson (1998) previously reported a gender effect, with data suggesting a decrease over time in daidzein and genistein excretion following chronic ingestion (1 month) of soya milk in women but no changes in the same study in male subjects. However, other studies have not observed any gender effects on urinary isoflavone recovery following the consumption of soya over similar study periods (Kelly et al. 1993; Lampe et al. 1998). Kelly et al. (1993) reported no differences in urinary isoflavone excretion in their male and female subjects following the ingestion of $40 \mathrm{~g}$ soya flour for $2 \mathrm{~d}$. Lampe et al. (1998) reported higher carbohydrate and fibre intake among female equol excreters compared with female non-equol excreters in the females, but not in their male subjects. Gender differences in plasma isoflavone pharmacokinetics have also been reported. Lu \& Anderson (1998) reported longer half-lives for daidzein and genistein in females compared with males, while in the rat, Slikker et al. (2001) reported that the area under the curve for genistein was greater in females compared with males. In the present study there was a trend towards premenopausal women excreting more genistein than males, suggestive of a potential gender effect. The present study appears to show a greater sensitivity of females to the type of food ingested to acute isoflavone dosing, although the effect of chronic feeding remains to be evaluated. However, we have previously demonstrated no significant difference in the physiological handling of ${ }^{13} \mathrm{C}$-labelled daidzein and genistein following the previous ingestion of soya milk compared with a single oral dose of these compounds
(Setchell et al. 2003b). The mechanism behind the gender difference is unclear. However, dietary factors such as fibre and carbohydrate have been previously associated with differences in the metabolism of daidzein to equol (Axelson et al. 1984; Cassidy, 1991; Lampe et al. 1998; Rowland et al. 1999; Setchell \& Cassidy, 1999). In the present study, subjects were studied on three separate occasions, where soya intake was randomly assigned. Although no dietary intake data were collected during the study periods, subjects were requested to consume their habitual diet and avoid soya-containing foods. Therefore the potential effect of other dietary components (for example, carbohydrate or dietary fibre) in explaining the observed differences cannot be addressed in the present study.

The data from females suggest that isoflavone excretion may be altered depending on the food matrix consumed. In both groups of women, the urinary genistein recovery was greater following the ingestion of soya milk compared with TVP and tempeh, although the difference in post-menopausal urinary genistein excretion between milk and tempeh was not significant. The available data suggest that purified daidzein and genistein are absorbed faster than isoflavones from soya foods (Izumi et al. 2000) but the present study is the first study to compare different food matrices.

Daidzein and genistein excretion accounts for approximately one-third of the total isoflavones ingested. In the present study, glycitein was not accounted for but the glycitein content of soyabean-derived products is small. The metabolism of daidzein and genistein in the intestine may account for some of the rest of the urinary isoflavones levels and various other metabolites have been identified in biological fluids (Axelson et al. 1984; Kelly et al. 1993; Joannou et al. 1995; Coldham et al. 1999). In the present study we focused on the metabolite of daidzein, equol, as a marker of intestinal metabolism. Equol has been the focus of much interest because it is more oestrogenic and a more potent antioxidant than daidzein (Shutt \& Cox, 1972; Arora et al. 1998, Mitchell et al. 1998). This suggests that this isoflavone metabolite may hold the key to understanding the mechanism of action and effectiveness of soya in clinical studies examining the potential health benefits of soya isoflavones. It is well established that only $30 \%$ of any given population group studied can produce equol (Cassidy et al. 1994, 1995; Lampe et al. 1998; Rowland et al. 1999). An inability to produce equol may be related to an absence of appropriate enzymes in the intestinal microflora or to an absence of bacterial species capable of producing equol (Axelson et al. 1984; Setchell et al. 1984). Its formation is exclusively related to intestinal microflora as germ-free rats do not excrete equol and the absence of equol from infant blood samples following soya infant-formula ingestion add weight to the need for an active microflora for its formation (Setchell et al. 1997). Our studies in healthy adults using $\left[{ }^{13} \mathrm{C}\right]$ daidzein and $\left[{ }^{13} \mathrm{C}\right]$ genistein show conclusively that equol is formed from daidzein and not genistein (Setchell et al. 2003b). The question of whether we can enhance the intestinal conversion of daidzein to equol is one of great interest (Axelson et al. 1984; Setchell et al. 2002) and dietary carbohydrate has been indicated as a factor 
that may determine equol production (Axelson et al. 1984; Cassidy, 1991; Lampe et al. 1998; Rowland et al. 1999; Setchell \& Cassidy, 1999). In the present study the urinary recovery of equol was higher following the ingestion of tempeh compared with the two other soya foods suggesting that a combination of a fermented and solid food matrix may enhance the production of equol. It is possible that a solid food matrix protects daidzein from degradation until it reaches the large intestine where it can be metabolised to equol by the microflora.

There was large variability in the incidence of equol production among the study population. Although the present study was too small to conduct valid statistical analysis on equol production, a higher proportion of post-menopausal women were consistently equol producers compared with the premenopausal women and men. The present data suggest that gender and age may be important determinants of intestinal isoflavone metabolism but larger studies are required to confirm these observations.

These data address the question of whether gender, age, food matrix or chemical composition influence urinary isoflavone excretion. In the present study population, urinary genistein excretion varied depending on the soya food consumed. Although the men studied showed no change in urinary isoflavones excretion between the soya foods, in women, a food-matrix effect was observed with higher levels of urinary genistein measured following soya-milk consumption. The isoflavone precursor, daidzein, unlike genistein, did not appear to be altered by age, gender or food matrix yet the urinary excretion of its intestinal metabolite, equol, was higher in women following the consumption of tempeh, suggesting a matrix and chemical-composition effect. Further studies are required to determine the relative importance of these factors in elderly populations, as to date much of the interest in soya isoflavones relates to post-menopausal health issues. Such data will help in defining optimal levels and delivery forms of these compounds for potential health benefits.

\section{Acknowledgements}

The Food Standards Agency (T05010) is thanked for funding this work. Professor Ken Setchell is thanked for analysing the soya foods used in the study. The authors thank Tony Dadd for statistical advice.

\section{References}

Arora A, Nair MG \& Strasburg GM (1998) Antioxidant activities of isoflavones and their biological metabolites in a liposomal system. Arch Biochem Biophys 356, 133-141.

Axelson M, Sjovall J, Gustafsson BE \& Setchell KDR (1984) Soya - a dietary source of the non-steroidal estrogen equol in man and animals. $J$ Endocrinol 102, 49-56.

Bannwart C, Adlercreutz H, Fotsis T, Wahala K, Mase T \& Brunow G (1984) Identification of $O$-desmethylangotensin, a metabolite of daidzein and matairesinol, one likely precursor of the animal lignan enterolactone in human urine. Finn Chem Lett 4-5, 120-125.

Bingham S \& Cummings JH (1983) The use of 4-aminobenzoic acid as a marker to validate the completeness of $24 \mathrm{~h}$ urine collections in man. Clin Sci 64, 629-635.

Cassidy A (1991) Plant oestrogens and their relation to hormone status in women. PhD thesis, University of Cambridge, Darwin College, Cambridge, UK.

Cassidy A, Bingham S \& Setchell K (1995) Biological effects of isoflavones in young-women: importance of the chemical composition of soyabean products. Br J Nutr 74, 587-601.

Cassidy A, Bingham S \& Setchell KDR (1994) Biological effects of a diet of soy protein rich in isoflavones on the menstrual cycle of premenopausal women. Am J Clin Nutr 60, 333-340.

Chen Z, Zheng W, Custer LJ, Dai Q, Shu XO, Jin F \& Franke AA (1999) Usual dietary consumption of soy foods and its correlation with the excretion rate of isoflavonoids in overnight urine samples among Chinese women in Shanghai. Nutr Cancer 33, 82-87.

Coldham NG, Howells LC, Santi A, Montesissa C, Langlais C, King LJ, MacPherson DD \& Sauer MJ (1999) Biotransformation of genistein in the rat: elucidation of metabolite structure by product ion mass fragmentology. J Steroid Biochem Mol Biol 70, 169-184.

Hutchins AM, Slavin JL \& Lampe JW (1995) Urinary isoflavonoid phytoestrogen and lignan excretion after consumption of fermented and unfermented soy products. J Am Diet Assoc 95, 545-551.

Izumi T, Piskula MK, Osawa S, Obata A, Tobe K, Saito M, Kataoka S, Kubota Y \& Kikuchi M (2000) Soy isoflavone aglycones are absorbed faster and in higher amounts than their glucosides in humans. J Nutr 130, 1695-1699.

Joannou GE, Kelly GE, Reeder AY, Waring M \& Nelson C (1995) A urinary profile study of dietary phytoestrogens - the identification and mode of metabolism of new isoflavonoids. J Steroid Biochem Mol Biol 54, 167-184.

Karr SC, Lampe JW, Hutchins AM \& Slavin JL (1997) Urinary isoflavonoid excretion in humans is dose dependent at low to moderate levels of soy-protein consumption. Am J Clin Nutr 66, 46-51.

Kelly GE, Nelson C, Waring MA, Joannou GE \& Reeder AY (1993) Metabolites of dietary (soya) isoflavones in human urine. Clin Chim Acta 223, 9-22.

King RA \& Bursill DB (1998) Plasma and urinary kinetics of the isoflavones daidzein and genistein after a single soy meal in humans. Am J Clin Nutr 67, 867-872.

Kirkman LM, Lampe JW, Campbell DR, Martini MC \& Slavin JL (1995) Urinary lignan and isoflavonoid excretion in men and women consuming vegetable and soy diets. Nutr Cancer 24, $1-12$.

Lampe JW, Karr SC, Hutchins AM \& Slavin JL (1998) Urinary equol excretion with a soy challenge: influence of habitual diet. Proc Soc Exp Biol Med 217, 335-339.

Lu LJW \& Anderson KE (1998) Sex and long-term soy diets affect the metabolism and excretion of soy isoflavones in humans. Am J Clin Nut 68, 1500S-1504S.

Mitchell JH, Gardner PT, McPhail DB, Morrice PC, Collins AR \& Duthie GG (1998) Antioxidant efficacy of phytoestrogens in chemical and biological model systems. Arch Biochem Biophys 360, 142-148.

Nagata C, Takatsuka N, Kurisu Y \& Shimizu H (1998) Decreased serum total cholesterol concentration is associated with high intakes of soy products in Japanese men and women. $J$ Nutr 128, 209-213.

Rowland I, Faughnan M, Hoey L, Wahala K, Williamson G \& Cassidy A (2003) Bioavailability of phyto-oestrogens. $\mathrm{Br} J$ Nutr 89, Suppl. 1, S45-S58.

Rowland I, Wiseman H, Sanders T, Adlercreutz H \& Bowey E (1999) Metabolism of oestrogens and phytoestrogens: role of the gut microflora. Biochem Soc Trans 27, 304-308. 
Setchell KDR (2000) Absorption and metabolism of soy isoflavones - from food to dietary supplements and adults to infants. $J$ Nutr 130, 654S-655S.

Setchell KDR, Borriello SP, Hulme P, Kirk DN \& Axelson M (1984) Nonsteroidal estrogens of dietary origin - possible roles in hormone-dependent disease. Am J Clin Nutr 40, $569-578$.

Setchell KDR, Brown NM, Desai P, Zimmer-Nechemias L, Wolfe BE, Brashear WT, Kirschner AS, Cassidy A \& Heubi JE (2001) Bioavailability of pure isoflavones in healthy humans and analysis of commercial soy isoflavone supplements. J Nutr 131, 1362S-1375S.

Setchell KDR, Brown NM \& Lydeking-Olsen E (2002) The clinical importance of the metabolite equol - a clue to the effectiveness of soy and its isoflavones. $J$ Nutr 132, 3577-3584.

Setchell KDR, Brown NM, Zimmer-Nechimias L, Wolfe BE, Jakate AS, Creutzinger V \& Heubi JE (2003a) Bioavailability, disposition and dose-response effects of soy isoflavones when consumed by healthy women at physiologically typical dietary intakes. J Nutr 133, 1027-1035.

Setchell KDR \& Cassidy A (1999) Dietary isoflavones: biological effects and relevance to human health. J Nutr 129, 758S-767S.

Setchell KDR, Faughnan MS, Avades T, Zimmer-Nechemias L, Wolfe B, Brashear W, Desai P, Oldfield M, Botting N \& Cassidy A (2003b) Comparing the pharmacokinetics of daidzein and genistein with the use of C-13-labeled tracers in premenopausal women. Am J Clin Nutr 77, 411-419.
Setchell KDR, Zimmer-Nechemias L, Cai JN \& Heubi JE (1997) Exposure of infants to phyto-oestrogens from soy-based infant formula. Lancet 350, 23-27.

Shutt DA \& Cox RI (1972) Steroid and phyto-estrogen binding to sheep uterine receptors in vitro. J Endocrinol 52, 299-310.

Slikker W, Scallet AC, Doerge DR \& Ferguson SA (2001) Gender-based differences in rats after chronic dietary exposure to genistein. Int J Toxicol 20, 175-179.

Wakai K, Egami I, Kato K, Kawamura T, Tamakoshi A, Nakayama T, Wada M \& Ohno Y (1999) Dietary intake and sources of isoflavones among Japanese. Nutr Cancer 33, $139-145$.

Watanabe S, Yamaguchi M, Sobue T, Takahashi T, Miura T, Arai Y, Mazur W, Wahala K \& Adlercreutz H (1998) Pharmacokinetics of soybean isoflavones in plasma, urine and feces of men after ingestion of $60 \mathrm{~g}$ baked soybean powder (kinako). J Nutr 128, 1710-1715.

Xu X, Wang HJ, Murphy PA, Cook L \& Hendrich S (1994) Daidzein is a more bioavailable soy milk isoflavome than genistein in adult women. $J$ Nutr 124, 825-832.

Zhang Y, Wang GJ, Song TT, Murphy PA \& Hendrich S (1999) Urinary disposition of the soybean isoflavones daidzein, genistein and glycitein differs among humans with moderate fecal isoflavone degradation activity. $J$ Nutr 129, 957-962.

Zubik L \& Meydani M (2003) Bioavailability of soybean isoflavones from aglycone and glucoside forms in American women. Am J Clin Nutr 77, 1459-1465. 